PRESERVING THE PAST: ARCHIVAL PRESERVATION OF OBSERVATORY PUBLICATIONS VIA AN OPTICAL DISK PROJECT

\author{
Brenda G. Corbin \\ U. S. Naval Observatory \\ Washington, D. C. 20392-5100
}

\begin{abstract}
Important research in astronomy and many star catalogues have been published in observatory publications during the last century and a half. Many of these older volumes are now in poor condition and conservation experts estimate they will not survive another 100 years if action is not taken. This paper describes a proposed project to preserve these volumes using optical disk technology.
\end{abstract}

\title{
1. THE PROBLEM
}

Much of the research in astronomy during the last 150 years has been reported in detail in observatory publications. Some series began in the early 1800's and some still continue until the present. Many important star catalogues have been published in these series. Although most star catalogues are now available on magnetic tape, critical material appears in the introductions which describe the telescope used, its behavior, and how the results were reduced, but this material is not available on magnetic tape.

Many of the older volumes of observatory publications are in very poor condition. This is caused by many things such as poor climatic conditions, dirt and heavy use, but the main enemy of the publications is the acidity of the paper on which they are printed. This acidity causes the pages to become very brittle, and the volumes literally fall apart in our hands, especially if they are photocopied. Conservation experts estimate that volumes such as these will not survive another century if preservation efforts are not undertaken.

An illustration of the problem can be given from the Naval Observatory collection. Some years ago 19th century observations of stars and planets were key-punched for a research project. These observations appear in various observatory publications, but the "GREENWICH OBSERVATIONS" were chosen first for key-punching. The volumes did fall apart as the key-punchers turned the brittle 19th century pages back and forth, punching and verifying. Some of the pages broke in the middle and others near the inner margin, 
so that the last column of figures was no longer legible. Many librarians can tell similar stories concerning many volumes in their collection. It is urgent that some kind of preservation program be undertaken so that the information in the 19th century volumes is still around in the $21 \mathrm{st}$ century.

\section{THE PAPER DESTRUCTION PROCESS}

Why do old, and some not-so-old pages of journals and observatory publications brown, split and crumble to dust? Paper made from the 15th through the 18 th centuries was produced by hand and was made from 1008 rag fiber. Much of that paper is just as good and supple today as the day it was made. However, the growing demand for paper in the 19 th century and a shortage of rags resulted in mass production techniques using wood pulp rather than rag fiber. The paper producers also began using an alum-rosin compound in order for the paper to better accept the printer's ink. This alum compound breaks down into acids which essentially eat the chemical bonds which hold the paper together. In this process the paper destroys itself. In many of the books published since 1850, this process is visible. The pages are yellowed and brittle, and easily broken when bent.

Today, archival or acid-free paper is being produced which has a lifetime of between 250 and 500 years. Although many university presses are now printing on this paper, its expense prohibits most publishers from using it.

\section{POSSIBLE SOLUTIONS}

Archival microfilming has long been the standard way to preserve documents for the future. If the proper film and storage conditions are used, the master copy can survive for perhaps several centuries. The problem with microfilm is that it is difficult to use, and it is very time consuming to find and copy the needed reference. However, archival microfilming is still considered one of the best ways of preservation at present (Calmes 1986).

Mass deacidification is another means for preserving large numbers of books (Shahani and Wilson 1987). This is a method in which chemical treatments can remove acid from book paper and stop further deterioration. Further research in various processes of this treatment is taking place at the Library of Congress in the United States, the Bibliotheque Nationale in France, and the National Library of Canada. This is a very expensive process which requires that the volumes treated have some strength left in the pages. Mass deacidification only halts the damage, it does not repair the acid damage suffered earlier.

The newest method available for book preservation is optical disk technology. In the USA, extensive pilot projects are underway at the Library of Congress and the Smithsonian Institution's National Air and Space Museum. Optical disk technology may revolutionize the preservation of library materials. 


\section{OPTICAL DISK TECHNOLOGY}

An optical disk pilot project is currently underway at the Library of Congress in Washington, D.C. (Price, 1984). Documents to be preserved are scanned at a resolution of 300 lines per inch and stored temporarily on magnetic disks, where the scanned material is reviewed for quality. The information is then transferred to an optical disk by a laser writing process. One side of a 12 inch optical disk can hold 3,000 - 10,000 pages of text depending on the distribution of black and white on the pages. The disks are stored in a "jukebox" which selects and plays them one at a time. To retrieve the information a reader uses a terminal, performs a search, and finds the appropriate citation. Using a command to display the text, the computer selects the correct disk in the jukebox, downloads the information into temporary magnetic disk storage, and displays the image on the terminal screen. One can page back and forth through the document and print pages if desired.

At present, an optical disk has a lifespan of approximately 10 years. However, the material can be transferred to a new optical disk with absolutely no loss of quality of text. It is also predicted that in the future disks will be developed which have longer lifespans.

\section{THE PRESERVATION PROJECT}

In 1980 , it was suggested that the Historical Astronomy Division of the American Astronomical Society might have some interest in supporting the preservation of the 19 th and early 20 th century series of observatory publications. A Preservation Committee was formed and the author and David DeVorkin of the Smithsonian's National Air and Space Museum were asked to examine the ways in which this project might be done. At that time, it was decided to proceed with archival microfilming and it was estimated that the entire project, including manpower, would cost approximately $\$ 220,000$. A cost sharing scheme was suggested in which observatories and universities would contribute half the amount, and national funding sources would be approached for the other half.

As some observatories and universities began to make their pledges, several people suggested that the new optical disk technology should certainly be considered for this project. After much discussion, it was decided that this "technology of the future" was the way to go with this project.

Optical disk technology is still being perfected and is in the pilot project stage in most institutions. It is hoped that within five years this project can begin, possibly in connection with the Smithsonian's National Air and Space Museum.

\section{THE FUTURE OF THE PROJECT}

Optical Disk Technology is perhaps the ideal solution for preservation of observatory publications of the 19 th and early 20 th centuries. Not only 
would the information contained in these volumes be preserved for future generations of astronomers and historians of astronomy, they would also be more widely available to all observatories. Most of the older observatories have almost complete sets of observatory publications. However, newer institutions, such as the Space Telescope Science Institute, must try to put together such sets by asking for duplicates from other observatories. This is a difficult, if not almost impossible task.

If such volumes were available through optical disks, they would be accessible to all institutions. Although the cost of computers which read and print the disks is prohibitive at present, this cost is expected to go down dramatically as the technology is perfected. As optical storage is also expected to be used in lieu of magnetic tapes in the future, most of the large institutions will probably have reading and printing equipment. Even if smaller observatories cannot afford such equipment, requests could be made to larger institutions which would have such facilities.

\section{ACKNOWLEDGEMENTS}

I would like to thank Joe Price, Director of the Optical Disk Pilot Program at the Library of Congress, for much useful information concerning this new technology and the project at the Library of Congress. David DeVorkin, National Air and Space Museum, Smithsonian Institution, has been actively involved in this preservation project from its inception, and has offered much help and encouragement to the author.

\section{REFERENCES}

Calmes, A. 1986, Libr. Jn1., 111, 38.

Price, J. 1984, Videodisc and Optical Disk, 4, 424.

Shahani, C. J. and Wilson, W.K. 1987, Amer. Sci. 75, 240. 